\title{
PLASMAPHERESIS-INDUCED CLINICAL IMPROVEMENT IN A PATIENT WITH STEROID-RESISTANT NEPHROTIC SYNDROME DUE TO PODOCIN (NPHS2) GENE MUTATION
}

\author{
Sylva Skálová1, Miroslav Podhola ${ }^{2}$, Karel Vondrák ${ }^{3}$, Gil Chernin ${ }^{4}$
}

Charles University in Prague, Faculty of Medicine and University Hospital Hradec Králové, Czech Republic: Department of Paediatrics ${ }^{1}$, Fingerland 's Department of Pathology'; Charles University, $2^{\text {nd }}$ Medical Faculty and Motol Faculty Hospital, Prague, Czech Republic: Department of Paediatrics ${ }^{3}$; University of Michigan, Ann Arbor, MI 48109, USA: Departments of Paediatrics and Human Genetics ${ }^{4}$

\begin{abstract}
Summary: Podocin mutations (NPHS2 gene) are mostly responsible for steroid-resistant nephrotic syndrome (SRNS) of childhood onset. Patients with NPHS2 gene mutations do not respond to corticoids and other immunosuppressive agents; partial remission can be rarely induced by cyclosporin A. We present a boy, where SRNS was diagnosed within first year of life. By the age of 15 years, proteinuria reached $9000 \mathrm{mg} / 24 \mathrm{~h}$, cholesterolemia $15 \mathrm{mmol} / \mathrm{L}$, albuminemia $19.6 \mathrm{~g} / \mathrm{L}$, in spite of combined therapy with cyclosporine A, methylprednisolone, enalapril and losartan. At that time a combined heterozygous form of two NPHS2 gene mutations (p.R138Q and p.V290M) was diagnosed, methylprednisolone was discontinued and patient underwent ten plasmapheresis procedures. This resulted in clinical improvement (proteinuria 3000 $\mathrm{mg} / 24 \mathrm{~h}$, S-cholesterol $6 \mathrm{mmol} / \mathrm{L}$, albumin $30 \mathrm{~g} / \mathrm{L}$ ) lasting for three years. In conclusion, plasmapheresis can result in clinical improvement and stabilization of SRNS caused by podocine mutation, before renal replacement therapy is initiated.
\end{abstract}

Key-words: Podocin; Steroid-resistant nephrotic syndrome; Plasmapheresis

\section{Introduction}

Nephrotic syndrome (NS) is a common childhood kidney disease caused by impaired glomerular function, characterized by protein leakage from the blood to the urine through the glomeruli, resulting in proteinuria, hypoalbuminemia, hypercholesterolemia and generalised oedema. NS is descriptively classified upon the patients' response to steroid treatment as steroid-sensitive NS (SSNS) or steroidresistant NS (SRNS). Podocin mutations (NPHS2 gene) are mostly responsible for SRNS of childhood onset $(3-5,8,9)$. The NPHS2 gene lies in the chromosome 1q25-q31 region and encodes a 383-aminoacid protein called podocin. Podocin is an integral membrane protein responsible for nephrin transport to membrane and for podocyte intracellular signalling. The lack of podocin results in extensive podocyte lesions and proteinuria $(1,5,9)$. Podocin mutations were identified in infants with early onset of SRNS and focal segmental glomerulosclerosis (FSGS), in patients with familial NS with autosomal recessive inheritance and in sporadic SRNS $(1,3-5,8,9)$. FSGS is identified in approximately $7-10 \%$ of renal biopsies in children. The incidence of FSGS has increased eleven-fold in two decades: between 1980 and 2000 from 0.2 to $2.3 \%$, respectively (11). Patients with NPHS2 gene mutations do not respond to corticotherapy. The treatment of these patients is mostly symptomatic using antihypertensive drugs with antiproteinuric properties, such as angiotensin-converting enzyme inhibitors and/or angiotensin receptor blockers. Beside partial response to immunosupression, in particular to cyclosporin A, no cases of complete SRNS remission were described and renal transplantation is the only therapeutic alternative (3,6-9). We present a patient with SRNS where plasmapheresis induced clinical improvement lasting for three years.

\section{Case Report}

A 5-month old boy presented with proteinuria (1000 $\mathrm{mg} / 1 \mathrm{~m}^{2} / 24$ hours), microscopic hematuria and hypoalbuminemia suggestive of NS. Corticotherapy (prednisone 60 $\mathrm{mg} / \mathrm{m}^{2}$ divided into 3 doses/day for 6 weeks, followed by 40 $\mathrm{mg} / \mathrm{m}^{2}$ as a single morning dose on alternate days for the next 6 weeks) together with levamizol and ketotifen had no effect, confirming the diagnosis of SRNS. First renal biopsy was performed at 4.5 years of age and histologic evaluation revealed FSGS. Cyclophosphamide $(2.5 \mathrm{mg} / \mathrm{kg} / \mathrm{day})$ and prednisone $(0.75 \mathrm{mg} / \mathrm{kg} /$ day $)$ treatment in the following 
four months was ineffective. Between four and nine years of age there was no progression of the disease, proteinuria was $1000 \mathrm{mg} / 24$ hours and therapy was not necessary. At nine years of age proteinuria exceeded $3000 \mathrm{mg} / 24 \mathrm{hours}$, the patient was treated with enalapril $(0.15-0.2 \mathrm{mg} / \mathrm{kg} /$ day $)$ and the second renal biopsy performed at 14 years of age did not show further progression of FSGS. Treatment with cyclosporine A ( $5 \mathrm{mg} / \mathrm{kg} /$ day) was initiated and methylprednisolone ( $1 \mathrm{mg} / \mathrm{kg} /$ every other day), enalapril $(0.3 \mathrm{mg} / \mathrm{kg} /$ day $)$ and losartan $(1 \mathrm{mg} / \mathrm{kg} /$ day $)$ were added. In spite of combined therapy, proteinuria reached $9000 \mathrm{mg} / 24$ hours, cholesterolemia $15 \mathrm{mmol} / \mathrm{L}$, albuminemia $19.6 \mathrm{~g} / \mathrm{L}$, and oedema appeared. At 15 years of age, a combined heterozygous form of two NPHS2 gene mutations (p.R138Q and p.V290M) was diagnosed, confirming diagnosis of autosomal recessive SRNS. Methylprednisolone was gradually tapered and withdrawn, fenofibrate ( $200 \mathrm{mg} /$ day) was added. Due to intractable course of NS, the boy was indicated for therapeutic plasmapheresis. The plasma exchanges were performed with the use 12 Fr x 6“ $(16 \mathrm{~cm})$ two-lumen hemodialysis catheterization set (Arrow International, Canada). The catheter was inserted into right subclavian vein. Fresenius polysulphone (PS2) dialyzer with surface of $0.5 \mathrm{~m}^{2}$ (Fresenius Medical Care, Bad Homburg, Germany) was implemented. BM11a/BM14 machine (Baxter, Unterschliessheim, Germany) was used for plasma separation. At each plasma exchange procedure, the plasma volume was exchanged at a rate of $1000 \mathrm{~mL} /$ hour. The removed plasma was substituted with $0.9 \%$ saline solution and $20 \%$ albumin in a $4: 1$ ratio. The patient also received heparin (Zentiva, Prague, Czech Republic), $33 \mathrm{IU} / \mathrm{kg} / 3$ hours. Single plasma exchange procedures were performed on a daily basis for the first four days, followed by six procedures every other day. Therefore, the patient underwent 10 plasma exchange procedures in 16 days. There were no adverse reactions. Concerning the cardiovascular and respiratory system, the patient remained stable throughout the therapeutic plasmapheresis cycle. Plasma exchanges resulted in drop in hypercholesterolemia to $6 \mathrm{mmol} / \mathrm{L}$. Six months after the plasmapheresis termination the patient had no oedema, proteinuria was $\sim 3000 \mathrm{mg} / 24$ hours, S-cholesterol 6 $\mathrm{mmol} / \mathrm{L}$, albumin $30 \mathrm{~g} / \mathrm{L}$, creatinine clearance $1.456 \mathrm{~mL} / \mathrm{s} /$ $1.73 \mathrm{~m}^{2}$. Cyclosporin A was discontinued after additional 2 months. These findings persisted for 3 years before proteinuria gradually reached $9.6 \mathrm{~g} / 24$ hours. Currently, six years after plasmapheresis, the patient is undergoing regular haemodialysis and is on a waiting list for renal transplantation.

\section{Discussion}

In our patient, two pathogenic NPHS2 gene mutations, each one segregating from a different parent, were found. Therefore, both maternal and paternal alleles have diseasecausing mutation resulting in SRNS. Patients with genetic
NS do not respond to corticoids and other immunosuppressive agents. Angiotensin-converting enzyme inhibitors and/or angiotensin receptor blockers are used to decrease blood pressure and proteinuria (6). Partial remission in SRNS can be induced by cyclosporine A (6-8), which was confirmed as superior to cyclophosphamide (7). Cyclosporine A therapy has so far resulted in partial remission in seven patients with NS due to NPHS2 mutations (6-8). It has been proposed that cyclosporine A stabilizes podocyte actin cytoskeleton, resulting in antiproteinuric effect (6). Plasmapheresis has been also reported to be effective in SRNS, as five sessions of plasma exchange induced remission in an eight-year old boy with otherwise therapy-resistant FSGS (10). Circulating glomerular permeability factors derived from $\mathrm{T}$ lymphocytes may play a crucial role in the protein excretion of nephrotic syndrome. Circulating glomerular albumin permeability factors were also detected in patients with primary FSGS. Plasma exchange is beneficial in these patients by removing the glomerular permeability factors and lipids. In addition to the removal of pathological agents such as antibodies, immune complexes and/or immune-associated cells, the removal of proinflammatory mediators including cytokines, chemokines and complements, and a demonstrated improvement of immune system have been postulated to contribute to the beneficial effects of apheresis (11). In our patient cyclosporine A did not induce partial remission. It is seems very likely that ten sessions of plasmapheresis significantly contributed to clinical improvement lasting for three years, as previous therapy with cyclosporine A, glucocorticoids, enalapril and losartan had no effect on clinical course of SRNS. The podocin gene should be evaluated in children with SRNS in order to determine further therapeutic strategy, as corticotherapy has no effect and cyclosporine A does not always induce partial remission. Plasmapheresis can result in clinical improvement and stabilization of SRNS caused by podocine mutation, before renal replacement therapy is initiated.

\section{References}

1. Boute N, Gribouval O, Roselli S, et al. NPHS2, encoding the glomerular protein podocin, is mutated in autosomal recessive steroid-resistant nephrotic syndrome. Nat Genet 2000; 24:349-54

2. Del Rio M, Kaskel F. Evaluation and management of steroid-unresponsive nephrotic syndrome. Curr Opin Pediatr 2008;20:151-56

3. Hinkes BG, Mucha B, Vlangos CN, et al. Nephrotic syndrome in the first year of life: two thirds of cases are caused by mutations in 4 genes (NPHS1, NPHS2, WT1, and LAMB2). Pediatrics 2007; 119:907-19.

4. Hinkes B, Vlangos C, Heeringa S, et al. APN Study Group. Specific podocin mutations correlate with age of onset in steroid-resistant nephrotic syndrome. J Am Soc Nephrol. 2008;19:365-71.

5. Karle SM, Uetz B, Ronner V, Glaeser L, et al. Novel mutations in NPHS2 detected in both familial and sporadic steroid-resistant nephrotic syndrome. Am Soc Nephrol 2002; $13 \cdot 388-93$.

6. Malina M, Cinek O, Janda J, Seeman T. Partial remission with cyclosporine A in a patient with nephrotic syndrome due to NPHS2 mutation. Pediatr Nephrol 2009 Jun 3. [Epub ahead of print]

7. Plank C, Kalb V, Hinkes B, Hildebrandt F, et al. Cyclosporin A is superior to cyclophosphamide in children with steroid-resistant nephrotic syndrome-a randomized controlled multicentre trial by the Arbeitsgemeinschaft für Pädiatrische Nephrologie. Pediatr Nephrol 2008;23:1483-93.

8. Ruf RG, Lichtenberger A, Karle SM, et al. Patients with mutations in NPHS2 
(podocin) do not respond to standard steroid treatment of nephrotic syndrome. J Am Soc Nephrol 2004; 15:722-32.

9. Vats AN. Genetics of idiopathic nephrotic syndrome. Ind J Pediatr 2005; $72: 777-83$
10. Vécsei AK, Müller T, Schratzberger EC, et al Plasmapheresis-induced remission in otherwise therapy-resistant FSGS. Pediatr Nephrol 2001;16:898-900.

11. Yokoyama H, Wada T, Furuichi K. Immunomodulation effects and clinical evidence of apheresis in renal diseases. Ther Apher Dial 2003; 7:513-519

Received: $25 / 10 / 2009$. Accepted in revised form: 17/05/2010.

\section{Corresponding author:}

Sylva Skálová, M.D., Ph.D., Department of Paediatrics, Charles University in Prague, Faculty of Medicine in Hradec Králové, Czech Republic; e-mail: skalova.s@seznam.cz 